\title{
ETHNICITY
}

\section{Toward health and wellbeing for indigenous Australians}

\author{
S M van Holst Pellekaan, L Clague
}

Postgrad Med J 2005;81:618-624. doi: 10.1136/pgmj.2004.031377

The health of indigenous Australians remains well below that of non-indigenous Australians and indigenous peoples in Canada and New Zealand. Although recent planning has initiated many outstanding, culturally appropriate programmes with indigenous involvement, health statistics only reflect marginal improvement in recent years. It is crucial that positive programmes are sustained with appropriately directed funding. An approach that includes respect for the emotional and spiritual wellbeing of Australia's indigenous peoples will assist to redress some of the disadvantage caused by dispossession of country, language, and identity. It is clear from many programmes that are in place, that primary health care delivered locally through community controlled organisations, will minimise the impact of serious illnesses that currently threaten whole families and communities. Westernised health care systems are slow to learn from indigenous peoples in Australia and other places, that maintenance of wellness, not management of illness should be the goal.

See end of article for authors' affiliations

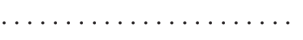

Correspondence to: Dr S M van Holst Pellekaan, School of Biotechnology and Biomolecular Sciences, University of New South Wales, Kensington, NSW 2052, Australia;

s.vanholst@unsw.edu.au

Submitted

8 December 2004

Accepted 30 March 2005
'Iriti pukulpa pika wiya nyinantia munu pūkulpa pika wiya kunpu nyinantiaku ngula. 'In the past we were happy and free from sickness; and in the future we will become strong and healthy again."

$\mathrm{T}$ hese words provide a strong message about time between the past and the future for the Anangu (Aboriginal) Pitjantjatjara people of central Australia. In an extraordinarily beautiful collection of stories and paintings we encounter the core concept of health and wellbeing embedded in the culture of communities within their own country. The wellbeing of individuals is not separable from the wellbeing of communities, because it encompasses spiritual, physical, social, and cultural wellness, linked to the land or country of the extensive social "family". Colonial history has impacted adversely on indigenous peoples in Australia, resulting in changed lifestyles stemming from dispossession of country, language, cultural identity, and disintegration of families. The forced removal of children from their families, sometimes to far and quite different regions of Australia, was on such a scale that the term "stolen generation" is, sadly, a very apt description. ${ }^{2}$
'Aboriginal health is not just the physical well being of an individual but is the social, emotional and cultural well being of the whole community in which each individual is able to achieve their full potential thereby bringing about the total well being of their community. It is a whole-of-life view and includes the cyclical concept of life-death-life.'. ${ }^{3}$

Although we recognise that in recent years westernised health delivery systems have broadened their aims to include a similarly holistic perspective, most mainstream health care still falls short in this regard, focusing on ill health but rarely on wellbeing. In Australia, health care delivery is all too often insensitive and inappropriate for indigenous Australians ${ }^{4-6}$ resulting in minimal use of available mainstream facilities. The health status of indigenous Australian peoples remains well below that of their nonindigenous counterparts in Australia and Indigenous peoples in Canada, North America, and New Zealand.

\section{AIM}

The intention of this review is to provide the reader with access to reported, readily available information about the current health status of indigenous Australians. A second aim, no less important in our view, is to increase awareness of the positive impact being made by the many excellent community controlled Aboriginal and Torres Strait Islander health programmes that are in place. This is more difficult for us to present with authority because the measurable impacts are not yet reflected in health statistics. To achieve this aim we ask the reader to explore the resources we provide and to reflect upon the need for health personnel to integrate professional knowledge and experience with sensitivity to the community based cultural values being expressed as more and more indigenous people become involved in creating their own programmes.

To establish the context necessary to address these two goals we summarise some background with regard to strategies at the national level and community based programmes. We then comment upon major causes of poor health while also providing, where possible, resources to explore the many excellent community controlled Aboriginal and Torres Strait Islander health programmes with sound long term goals that are in place.

\section{BACKGROUND \\ National issues}

Aboriginal and Torres Strait Islander peoples constitute a small proportion of the total 
population in Australia, the 2001 census figures being $458520^{78}$ or around $2 \%$. Most live in the state of New South Wales, followed by Queensland, Western Australia, the Northern Territory, Victoria, South Australia, Tasmania, and the Australian Capital Territory. Considerable variation exists in the type of community in which indigenous people live in the different states and territories, from large cities and heavily populated coastal regions to towns, rural, and remote areas. The statistics require reflecting upon because, although numbers who live in some cities appear highest, they constitute around $1 \%$ of total city dwellers whereas in remote areas indigenous people constitute around $40 \%$ of that population segment. Events of recent history have dispossessed indigenous people of their land, language, and traditional culture yet communities have retained and/or regained a strong and resilient identity, wherever they may live. Figure 1 summarises the main factors that impact upon indigenous communities and that are obstacles to achieving improvement in health. While the beauty of indigenous art, dancing, and music is now appreciated throughout the world, most indigenous Australians remain disadvantaged in their own country, this status nowhere more starkly shown than in health statistics.

Government strategies aimed at improved Aboriginal health status were proposed in the National Aboriginal Health Strategy. ${ }^{3}$ The results envisaged were not being realised at evaluation, and several recommendations were put forward. ${ }^{9}$ Neither at that time nor today have those recommendations been endorsed by the government of the day. Goals have been revised and renewed ${ }^{10}{ }^{11}$ but the political process of revising the administration of indigenous affairs remains tortuous and delays implementation of planned strategies. ${ }^{12}$ Expenditure on indigenous health is perceived to be high by the average Australian taxpayer. Per capita funding is higher for indigenous compared with nonindigenous health, but it would seem that the funds do not reach the people for whom it is intended. Figures suggest that spending through the federal MBS (Medical Benefits Scheme) and PBS (Pharmaceutical Benefits Scheme) amounted to $\$ 224$ per capita for indigenous people compared with \$601 per non-indigenous person in 1998-9. In real terms the spending per indigenous person is only $1.2 \%$ higher than per capita funding for the general population but on a relative needs basis this should be $2.2 \% .{ }^{13}$ The discrepancy is probably attributable to unwillingness to access mainstream services and/or availability of services, especially in remote areas. Major political parties have not adequately addressed the reason behind these figures.

\section{Community based programmes}

However, it is extremely important that all health personnel are aware of the many outstanding primary health care programmes that are in place and to understand how important it is to sustain these sorts of programmes to see real progress in the future. Several communities have devised programmes that address fundamental issues and set long term goals. It is difficult to quantify improvements that have been made in recent years at a national level, partly because, for a variety of reasons, indigenous Australians are not identifying or being identified in records of some administrations. Some excellent community controlled programmes bring primary health care, antenatal services, birthing support, and follow up contact to families and communities, bridging the gap between mainstream services and local groups. These approaches address basic issues of housing and healthy living in the context of the local community, central to people's comfort. ${ }^{14-16}$ Of note are those that focus on the care of mothers and babies by encouraging antenatal progress visits. Two examples of such programmes are "Strong mothers, strong babies, strong culture"17, and "Ngunytju Tjitji Pirni"/Caring for women and children. ${ }^{18}$ Another allows, where possible, privacy and/or the inclusion of traditional practices during childbirth. ${ }^{19}$ These approaches engender some measure of family trust in health care delivery upon which continued positive interest can be encouraged. The reader is encouraged to explore the many internet sites and links that are provided and is also asked to respect specific requests that might be made (for instance, if a particular programme is designed for women, men may be asked not to connect to that link). Postnatal visits and ongoing attention to the health of children through collaboration with school programmes, and strategies such as the involvement of children in the preparation of colourful audio-visual material for stimulating interest in healthy living, must result in a steady improvement in overall health status of communities over the next generations.

Essential to the success of these approaches is the employment and cooperation of trained indigenous health personnel who are sensitive to the specific cultural needs of different communities and who understand the reasons for discomfort with western methods. Also crucial is that nonindigenous people have adequate preparation about indigenous issues and most importantly a willingness to learn as well as teach. ${ }^{5}$

As an example we describe briefly the experience of one of us (LC) in working with others on "The National Cancer Screening Program: Remote Community Education and Clinical Training Project, Family Planning Welfare Northern Territory". The aim of the project is to provide training to remote nursing professionals including Aboriginal health workers (AHWs), to conduct Pap smears among women attending women's health clinics in rural and remote areas. Preference is given to nursing professionals who have not participated in Pap smear training previously and can also be offered to GPs who are interested in improving or updating their skills. Initially, there were three Aboriginal communities chosen for receiving training and resources about cervical screening. These communities were chosen because of their current low rates of cervical screening. Of the three communities visited, two workshops in each community with local women in attendance were carried out. The facilities of the "Strong mothers, strong babies, strong culture" programme were used on each occasion. The number of women attending these sessions ranged from 8 to 11 participants. Some difficulties were encountered during planning and implementation:

- Inability to access the Northern Territory Pap Smear register for a variety of reasons.

- Limited time frame for project implementation with the result that the number of recipient communities planned was reduced from six to three and some were grouped to make travel time more efficient.

- The logistics of networking with key service providers such as Danila Dilba (Aboriginal controlled Health Service in Darwin), health workers in the chosen communities, district medical officers, and the women's health nurses in such a short amount of time was not without its limitations.

- The process of networking and making sure the communities were informed was slow; information was not passed on with regards to the project. The contact person at the beginning of the project commencement in one community had changed by commencement of the educational activities of June 2003 and all communities involved were short staffed.

- The recognition of culturally appropriate behaviour resulted in reduced ability to do Pap smears in one 


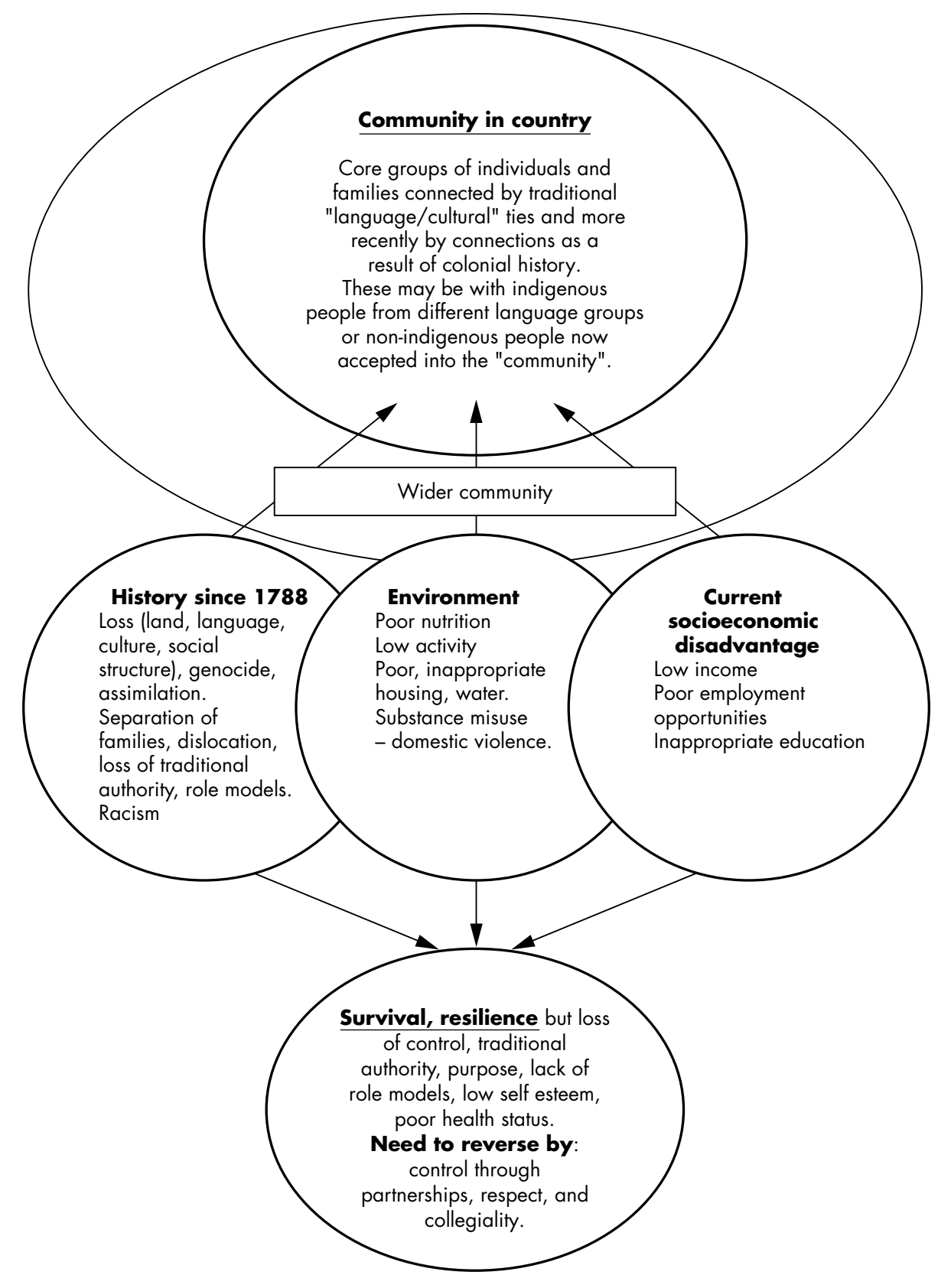

Figure 1 A summary of factors that impact on the health of indigenous Australians.

Core groups of individuals and families connected by traditional language/cultural" ties and more recently by connections as a result of colonial history. These may be with indigenous or non-indigenous people now accepted into the "community".

community. The clinic closed out of respect due to a death in the community.

- The actual project was not accredited, which would be desirable, however the team introduced a certificate of attendance for all seminars and workshops that took place.

- The need for the ongoing process was initiated with the networking of staff at Gove Hospital. Personnel of the women's health unit visited the communities a week after family planning, spent a week carrying out Pap smears in two of the three communities, Ramingining and Gapuwyak. However, this in no way increased overall cervical screening rates, one of the outcome measures, to any great level.

The team concluded that there are considerable issues that still need to be addressed with regards to Pap smear screening rates and how to train staff when there is continual turnover of personnel, but that this programme and others like $\mathrm{it}^{20}$ are likely to achieve desired outcomes.

The seriousness of poor indigenous health status has been obvious for decades and known within Australian health systems. Communities themselves need to be assisted to understand the extent and severity of problems, ${ }^{21}$ for the survival of many is at stake. This part of the review provides summarised information on the current health statistics for indigenous Australians from several resources for which a wealth of detail is available. Main factual information is available from the Australian Institute of Health and Welfare $^{22}$ and Australian Indigenous Health InfoNet $^{8}$ that also provide links to other online sites. The Aboriginal and Islander Health Worker Journal ${ }^{23-25}$ is cited because readers can access a broad range of writing on many topics including the experiences of professional indigenous health personnel providing stories of achievements. The journal also shows ways of disseminating information to health personnel 
in forms appropriate for community information at different levels, and it also provides direction to primary sources.

\section{CURRENT INDIGENOUS HEALTH STATUS}

Mortality rates for indigenous Australians compared with those for non-indigenous Australians remain disproportionate with some evidence that the gap has widened recently. ${ }^{26}$ The life expectancy for indigenous men is 56 years ( 21 years less than for the total male population) and for women 63 (20 years below the expectancy for the total female population). Taking into account the fact that some indigenous deaths may not be recorded as such and that the indigenous population is overall younger than the nonindigenous population, it is possible that the death rate for indigenous Australians is four times that of non-indigenous Australians. ${ }^{8}$ This is equivalent to saying that the current mortality rate for indigenous Australian men is the same as a non-indigenous man in 1901-10 or a male born now in war torn Sudan. Life expectancy for indigenous women equates to that for non-indigenous women in 1920 or women born in Iraq in 2000.

Leading causes of death for indigenous and for all Australians in 2000-2001 were cardiovascular disease, followed by injury and poisoning (includes accidents, self harm, and assault), neoplasm, respiratory and endocrine or metabolic disease (especially diabetes). However, in each category, death rates for indigenous people exceeded those of non-indigenous Australians. Perinatal death rates remain distressingly high for indigenous families in Queensland, Western Australia, South Australia, and the Northern Territory but because of the difficulty of ascertaining indigenous status in the records of other states, it is not possible to see national trends. ${ }^{22}$ Overall, indigenous women have more children and at a younger age than nonindigenous women. On average, the birth weight of indigenous babies is lower than that of non-indigenous babies, a reported exception being through the Nganampa Health Council programme where perinatal death rates are reported to have improved from 45.2/1000 to 8.6/1000 and low birthweight babies reduced from $14 \%$ in the early 1980 s to $6 \%$ in $2003,{ }^{10}$ a clear example of what can be achieved. In other areas available data are sparse, reinforcing the point that soundly researched base statistics specific to indigenous health are necessary as well as those applicable to the wider society. Clearly, perinatal health status is one of the most fundamental areas for which sound information about mothers and babies is essential for both immediate health information and early identification of potential problems, thus relevant to long term health.

The incidence and severity of health conditions in indigenous Australians that lead to death is also disproportionate, occurring at an earlier age than for other Australians. For a large part these illnesses stem from socioeconomic disadvantage that generates risky lifestyle factors including misuse of tobacco, alcohol, and other drugs and from the lack of role models as family structures were broken down. Of these, alcohol misuse and petrol sniffing are major problems in many communities. The following section identifies types of health problem affecting indigenous Australians. Several health conditions are categorised together, not because there are never separate causes, but because several conditions are commonly associated. We do not repeat statistics that are available in the references already cited to which the reader is directed. More usefully, we draw attention to how some approaches to health care delivery are responding to the needs of indigenous communities.

\section{Diabetes, obesity, cardiovascular disease, and end} stage renal disease

An association between type 2 diabetes, obesity, physical inactivity, and cardiovascular disease has long been recognised in all populations and in indigenous Australians the incidence is exacerbated by stress related to dispossession, high levels of cigarette smoking, alcohol consumption, inappropriate diets for activity levels, inadequate antenatal care, low birth weight, and poor infant health. Predisposition to type 2 diabetes has been seen in indigenous Australians and other indigenous populations, apparently amplified by a rapidly changed diet and lifestyle in populations where genotypes have evolved to be successful under different conditions. ${ }^{27}$ The long term effects of type 2 diabetes in all populations arise from the association with hypertension, coronary heart disease, microvascular complications in the eyes, kidneys, and peripheral nervous system. Pioneering work in this area is that of $\mathrm{O}^{\prime}$ Dea and others, identifying factors in the relation between nutrition, lifestyle, and disease. ${ }^{28}$ A number of metabolic characteristics seem to be associated with predisposition to lipid related disorders in Aboriginal Australians on a "westernised diet". Carbohydrate and lipid profiles from a group on a westernised diet were compared with another group of indigenous Australians from north east Arnhem Land living a nearly traditional lifestyle with a very different diet, showing that the "traditional" group were lean, had low fasting blood glucose, and low fasting cholesterol in contrast with the other group. However, their insulin concentrations were similar to the first group, and higher than non-indigenous Australians. ${ }^{28}$ McDermott $e t$ $a^{29}$ reported the beneficial effect of the "Homelands" movement on health in central Australian indigenous people who lead a more active and motivated lifestyle, with less reliance on a western diet. Born out of the experience in dealing with prevalence and an excess of complications of type 2 diabetes in indigenous Australians in northern Australia, McDermott et $a l^{30}$ make a renewed plea to improve primary health care strategies. They urge a focus on early detection, utilisation of resources available, such as dietary information and implementation of ongoing planning with patients and families to ensure quality care and minimisation of complications.

Cardiovascular disease remains more highly prevalent in indigenous than in non-indigenous Australians and is often associated with type 2 diabetes. Wang and $\mathrm{Hoy}^{31}$ investigated the impact of diabetes on coronary heart disease (CHD) risk in indigenous men and women. Their findings suggested, consistent with studies elsewhere, that CHD risk for the women was increased if they have type 2 diabetes, highlighting the need to understand physiological pathways leading to the conditions. Understanding specific cause entails understanding "predisposition" and "familial tendencies" as well as the known life style risk factors. Genetics studies to investigate "candidate" genes for these disorders in many groups worldwide are underway, ${ }^{32}$ but because of the complexity of the underlying metabolic pathways, results that may facilitate early diagnosis and improved treatment are a long way off. Ongoing research is required using a coordinated approach to understanding the phenotype/ genotype relation and the epistatic processes underlying genetic tendencies.

The long term complications of these conditions include renal failure and there is now an alarming increase in the need for kidney dialysis and transplant. Management of dialysis poses enormous problems geographically, socially, technically, and economically for individuals, families, and health personnel and are a burden on the health care system especially in rural and remote areas. Haemodialysis is the most common form of treatment for chronic renal disease but 
is clearly dependent on available clinics or hospitals and in remote areas this is either unavailable or means that patients and families are dislocated from country and community. Withdrawal from treatment is not uncommon in the Northern Territory. Alternatively, peritoneal dialysis is an option but still requires careful administration and compliance, not always practical in remote areas. If the incidence of the conditions leading to renal disease can be minimised early in life, the complications are less likely to occur and significant improvement in quality of life must follow, while the burden on the health care system must be eased.

\section{Neoplasms}

There is some uncertainty about the incidence of cancer, probably because indigenous status may be under identified in cancer registers, but overall deaths from cancer are less in indigenous people than the total population. However, this is not the case for some types of cancer, such as smoking related tumours, emphasising the importance of antismoking education programmes. ${ }^{33}$ Cervical cancer has a higher incidence than breast cancer and both of these are likely to be reduced if appropriately sensitive screening procedures are in place and the service is taken to remote areas. ${ }^{34}{ }^{35}$ The experience of one of us (LC) in this process, described above, shows some of the implementation issues of such programmes and the need for follow up, sustained effort, and re-evaluation of programmes. The incidence of liver cancer is relatively high, possibly related to the high rate of hepatitis.

\section{Respiratory problems}

Respiratory illness accounts for higher levels of hospitalisation and GP visits for indigenous compared with nonindigenous especially in infancy and childhood where the cause is infection or asthma. ${ }^{36}$ Upper respiratory tract infections in childhood stem from issues related to overcrowded, inadequate housing, and inappropriate diet. Ear infections arise both as complications of common colds, influenza, and other causes and the importance of early treatments to avoid permanent damage cannot be overestimated. In many communities, a close relationship between health and education personnel permits the constant checking of the ears and hearing ability of children through schools, so that damage from chronic infections can be minimised. In older people, respiratory conditions are often lung cancer/emphysema after a life of smoking, again underlining the importance of primary health care education programmes.

\section{Key references}

- Australian indigenous Health/nfoNet, 2004. http:// www.healthinfonet.ecu.au/html_keyfacts/overviews_190104.pdf

- NHMRC. Nutrition in Aboriginal and Torres Strait Islander peoples. An information paper. National Health and Medical Research Council, 2000.

- OATSIH. Office for Aboriginal and Torres Strait Islander Health. National strategic framework for Aboriginal and Torres Strait Islander Health, 2004. http://www.health.gov.au/oatsih/pubs/

- O'Donoghue L. Toward a culture of improving Indigenous health in Australia. Aust J Rural Health 1999:9:64-9.

- Pholeros P, Rainbow S, Torzillo. Housing for health. Toward a healthy living environment for Aboriginal Australia. Newport Beach: Health Habitat, 1993.

\section{Infectious diseases}

Conditions arising from skin infections, ${ }^{37}$ upper respiratory tract and eye infections, including trachoma and the ensuing complications (see MacNamara ${ }^{38}$ and Amos et al ${ }^{39}$ ) are manageable with sustained programmes and, to a large extent, avoidable with proper attention to housing and hygiene. Also essential is the availability of immunisation programmes and the appropriate education to encourage utilisation of services. ${ }^{24}$ Gastrointestinal infections are common and those such as salmonellosis and the presence of Helicobacter pylori are under-researched. More serious because of cardiovascular complications, is rheumatic fever, which has a high incidence ${ }^{40}$ in Aboriginal children in contrast with non-indigenous children. Other infectious diseases of great concern are hepatitis, TB, STIs, HIV/ AIDS $^{41}{ }^{42}$ that have an almost overwhelming impact on some communities. We urge the reader to explore resources, not only to understand the reasons for such serious situations but to appreciate how central is the need for sound primary health care and education programmes implemented by dedicated personnel, for we are unable to do justice to these issues here.

\section{Injury}

Injury, which includes accident, self harm, and substance misuse accounts for a distressingly high impact on health and wellbeing, much of which stems from socioeconomic disadvantage and the impact of history on morale and spiritual wellbeing. It must be noted that most indigenous Australians do not use alcohol but where consumption is heavy, the flow-on to families and social groups is reflected in terrible disorder, violence, and social breakdown. Past policies tended to regard alcohol misuse separately from health and were essentially judgemental in regards to indigenous people, the influences of history and culture on drinking habits not understood. Many communities tackle the issue head-on, restricting alcohol, running night patrols to pick up inebriates, and confronting those who break the rules but the ability to sustain strategies is impeded by influences of the outside world. Brady ${ }^{43}$ points out the value of careful use of authority by people external to the families involved, sometimes more readily accepted than from within the social network. Extensive work has been and is being done to appropriately improve strategies and resources for people working with alcoholism. ${ }^{43-49}$ Issues arising from domestic violence, ${ }^{50-52}$ and mental health issues ${ }^{53}$ constitute important areas of concern but are far too complex to explore here. Of confirmed value are local support teams and also the sort of education resources that present serious issues to communities in familiar contexts such as films, pamphlets, workshops, ${ }^{24}$ and even performances set in indigenous communities with indigenous actors. They carry a powerful message.

\section{CONCLUSIONS}

Currently, indigenous Australian health status remains well below acceptable levels. Improvement will be forthcoming if sustained development of culturally appropriate programmes with a high level of indigenous control occurs. ${ }^{54}$ Central to this theme is the development of partnerships between locally run services with substantial numbers of indigenous personnel working cooperatively with mainstream services and specialist centres. This is happening in many communities but it requires a high level of apolitical tenacity and commitment from those involved in both planning and delivery, strongly supported at the highest level of administration and government. This means that there is increased funding ${ }^{13}$ directly for health services, especially in remote areas and for education. This should mean increased 
opportunities for accessible training for indigenous personnel at all levels including local health workers ${ }^{55}$ and adequate cultural awareness for non-indigenous people, especially health professionals. The education issues have been addressed by many professional bodies and universities but require ongoing support with adequate resources. Thus there has to be a will and a commitment to improving the social and emotional wellbeing of whole communities, a commitment that has to come from governments of whatever persuasion as well as that of education institutions, health organisations, and health professional individuals. Programmes need to be accessible, acceptable, and appropriate. They should focus on primary health care especially early in life, aiming at prevention or identification of problems before they became serious, coupled with ongoing recall and reminder to monitor progress. ${ }^{30}$ Essential to these aims is the maintenance of accessible services with mobile clinics or frequent community visits, especially in rural or remote areas. While these strategies may seem to be expensive to maintain, they are user friendly and the long term benefits should be cost effective because the chances of progression to serious illness requiring expensive treatment are minimised.

The existing partnership arrangements between regional community controlled organisations and mainstream health need to be sustained and used as models for further development. ${ }^{12}$ More programmes also need to address specific areas such as men's health, women's programmes, mothers, babies, and early childhood because participation in these programmes will flow through to whole families and communities. Improved family role models and increased community involvement will lead to increased confidence so that young people will believe that they have some control over their own pathways in the wider community. Of benefit is the exchange of experiences with other indigenous peoples that has been occurring over recent years, increasing awareness that indigenous peoples of Canada, North America, and New Zealand are shortening the gap with improved health in contrast with indigenous Australians. While this is heartening to health personnel there is a need for more structured exchange at international government level and it is hoped that the current Memorandum of Understanding between the Canadian Institutes of Medical Research, the National Medical Research Council of Australia, and the Health Research Council of New Zealand will result in the development of useful strategies. Australia must close the gap.

With a willing, sustained, and committed effort by cooperative partnerships from national to local levels, a return to good health envisaged by the Anangu will become a reality. For the elders who have survived the pain and sadness of recent history, some measure of spiritual healing is then also possible.

\section{ACKNOWLEDGEMENTS}

We acknowledge the traditional custodians of country in which reside the communities we have mentioned. We also pay tribute to the many strong indigenous and non-indigenous people working in Australia and other countries in the area of indigenous health.

\section{Authors' affiliations}

S M van Holst Pellekaan, School of Biotechnology and Biomolecular Sciences, University of New South Wales, Kensington, New South Wales, Australia

L Clague, Department of Family and Community Nursing, Faculty of Nursing M02, University of Sydney, New South Wales, Australia

Funding: none.

Competing interests: none.

\section{REFERENCES}

1 HALT (Healthy Aboriginal Life Team). Anangu way. Alice Springs: Nganampa Health Council, 1991.

2 HREOC. Human Rights and Equal Opportunity Commission. Bringing them home. Report of the National Inquiry into the separation of Aboriginal and Torres Strait Islander children from their families. Canberra: Commonwealth of Australia, 1997.

3 NAHS. National Aboriginal Health Strategy Working Party 1989. A National Aboriginal Health Strategy. Canberra: Australian Government Publishing Service, 1996, http://www.health.gov.au/oatsih/pubs/, 1989.

4 Eckermann AE, Dowd T, Martin M, et al. Binan Goonj: bridging cultures in Aboriginal health. Armidale: University of New England, 1992.

5 van Holst Pellekaan SM. Learning to listen to Aboriginal and Torres Strait Islander people. In: Gray G, Pratt R, eds. Issues in Australian nursing 5: the nurse as a clinician. Melbourne: Churchill Livingstone, 1995:71-84.

6 Henry BR, Houston S, Mooney GH. Institutional racism in Australian healthcare: a plea for decency. Med J Aust 2004;180:517-20.

7 ABS. Australian Bureau of Statistics. Canberra: Australian Bureau of Statistics, 2002, http://abs.gov.au, 2002.

8 Australian Indigenous Health/nfoNet, 2004. http:// www.healthinfonet.ecu.au/html_keyfacts/overviews_190104.pdf.

9 NAHS. National Aboriginal Health Strategy Evaluation Committee 1994. National Aboriginal health strategy, evaluation. Canberra: Australian Government Publishing Service, 1994.

10 NATSIHC. National Strategic Framework for Aboriginal and Torres Strait Islander Health: Context. National Strategic Framework for Aboriginal and Torres Strait Islander Health: framework for action by Governments, NATSIHC, Canberra, 2003. http://www.health.gov.au/oatsih/pubs/.

11 OATSIH. Office for Aboriginal and Torres Strait Islander Health. National strategic framework for Aboriginal and Torres Strait Islander Health, 2004. http://www.health.gov.au/oatsih/pubs/.

12 National Aboriginal Community Controlled Health Organisation (NACCHO). Submission to the Senate Select committee on the Administration of Indigenous Affairs. Canberra: NACCHO, 2004. http://www.aph.gov.au/Senate/ committee/indigenousaffairs_ctte/submissions/sub179.

13 Econtech Pty. Costing models for Aboriginal and Torres Strait Islander health services. Consultant Report No 3, Review for the Australian Government's Aboriginal and Torres Strait Islander Primary Health Care Program. Canberra: Commonwealth of Australia, 2004.

14 Pholeros P, Rainbow S, Torzillo P. Housing for health. Toward a healthy living environment for Aboriginal Australia. Newport Beach: Health Habitat, 1993.

15 Nganampa Health Council. http://www.nganampahealth.com.au.

16 Maari M. http://www.webtester6.tripod.com.

17 Mackerras D. Birth weight changes in the pilot phase of the 'Strong Women, Strong Babies, Strong Culture' program in the Northern Territory. Aust N Z J Public Health 2001;25:34-40.

18 Ngunytju Tiiti Pirni/Caring for Women and Children http://www.ntp.org.au.

19 CAAC. Central Australian Aboriginal Congress Inc, 2003. http:// www.cacongress.com.au.

20 Coory MD, Fagan PS, Muller JM, et al. Participation in cervical cancer screening by women in rural and remote Aboriginal and Torres Strait Islander communities in Queensland. Med J Aust 2002;177:544-7.

21 Weeramanthri T, Plummer C. Land, body and spirit-talking about adult mortality in an Áboriginal community. Aust J Public Health 1994; 18:197-200.

22 Australian Institute of Health and Welfare. Australia's health 2004. Canberra: AlHW, 2004, http://www.aihw.gov.au.

23 AlHWJ. Aboriginal and Islander Health Worker Journal, 2004. http:// www.aihwj.com.au.

24 AlHWJ. The indigenous health promotion resources guide. 4th ed. Matraville, NSW: Aboriginal and Islander Health Worker Journal, 2004.

25 AlHWJ. From health worker to health worker. An annotated index of indigenous health information. Aboriginal and Islander Health Worker Journal, 1996-2003, 2004.

26 Ring I, Firman D. Reducing indigenous mortality in Australia: lessons from other countries. Med J Aust 1998; 169:528-9, 532-3.

27 O'Dea K. Westernisation, insulin resistance and diabetes in Australian Aborigines. Med J Aust 1991;155:258-64.

28 NHMRC. Nutrition in Aboriginal and Torres Strait Islander peoples. An information paper. National Health and Medical Research Council, 2000 http://www.nhmrc.gov.au/publications/synopses/n26syn.htm.

29 McDermott R, O'Dea K, Rowley K, et al. Beneficial impact of the Homelands Movement on health outcomes in central Australian Aborigines. Aust N Z J Public Health 1998;22:653-8.

30 McDermott RA, Tulip F, Schmidt B. Diabetes care in remote northern Australian Indigenous communities. Med J Aust 2004;180:512-16.

31 Wang Z, Hoy WE. Association between diabetes and coronary heart disease in Aboriginal people: are women disadvantaged? Med J Aust 2004;180:508-11.

32 Busfield F, Duffy DL, Kesting JB, et al. A genome wide search for type 2 diabetes-susceptibility genes in Indigenous Australians. Am J Hum Gene 2002;70:349-57.

33 Gill J. The lung story. Aboriginal and Islander Health Worker Journal 1999;23:7-8.

34 Fagan P. Breast cancer screening for remote area indigenous women in far north Queensland-is it relevant? Aboriginal and Islander Health Worker Journal 1998;22:2-4.

35 Kong G. Breast cancer and Aboriginal and Torres Strait Islander women-a national report. Aboriginal and Islander Health Worker Journal 1998;22:3-5. 
36 Dawson A, Russell, Caponi A. Asthma project at Pika Wiya Health Services: identifying barriers and developing resources. Aboriginal and Islander Health Worker Journal 2003;27:20-2

37 Wong L, Amega B, Barker R, et al. Factors supporting sustainability of a community-based scabies control program. Australas J Dermatol 2002;43:274-7.

38 MacNamara B. Vision 2020: The right to sight-Australia. Aboriginal and Islander Health Worker Journal 2000;24:23.

39 Amos B, Bailes B, Baxter S, et al. Report: an eye health program for Aboriginal health workers in South Australia. Aboriginal and Islander Health Worker Journal 2002;26:22-4.

40 Franks C. Who is at risk of contracting acute rheumatic fever in Australia? Aboriginal and Islander Health Worker Journal 2002;26:23-32.

41 McDonald A. Human immunodeficiency virus and acquired immune deficiency syndrome. Revised Australian case definition for HIV infection. Aboriginal and Islander Health Worker Journal 2002;26:25.

42 Costello M. HIV/AIDS and us mob. Aboriginal and Islander Health Worker Journal 2003;27:3-4

43 Brady M. Indigenous Australia and alcohol policy meeting difference with indifference. Sydney, Australia: University of New South Wales Press, 2004

44 Hunter E. Aboriginal health and history: power and prejudice in remote Australia. Cambridge: Cambridge University Press, 1993.

45 Flick B. Getting in before the heart starter-controlling alcohol, violence, and environmental hazards - early intervention available to communities. Aboriginal and Islander Health Worker Journal 1996;20:13-14.
46 Brady M. The grog book: strengthening indigenous community action on alcohol. Canberra: Commonwealth Department of Health and Family Services, 1998.

47 Brady M. Hunter E. Talking about alcohol with Aboriginal and Torres Strait Islander patients. A brief intervention for health professionals. Canberra: Centre for Aboriginal Economic Policy Research, Australian National University, 2003.

48 Wilson S. Indigenous substance misuse update. Aboriginal and Islander Health Worker Journal 2001;25:16-17.

49 Redfern AMS. AMS Redfern Drug and Alcohol Service. Aboriginal and Islander Health Worker Journal 2001;25:24.

50 Clarence C, MacDonald. Lajamanu -women working together. Aboriginal and Islander Health Worker Journal 1998;22:2-3.

51 Fitzgerald J, Weatherburn. Aboriginal victimisation and offending: the picture from police records. Aboriginal and Islander Health Worker Journal 2002;26:26-8.

52 Gentle I, Taylor J. A community taking control of family violence. Aboriginal and Islander Health Worker Journal 2002;26:4-6

$53 \mathrm{O}$ 'Shea K. Men and mental health. Aboriginal and Islander Health Worker Journal 1997;21:15-16.

54 O'Donoghue L. Toward a culture of improving Indigenous health in Australia Aust J Rural Health, 1999;9:64-9.

55 Aboriginal and Torres Strait Islander Health Workforce Working Group. http://www.health.gov.au/oatsih/pubs/atsihwwg.htm. 